\title{
Allocation of the Book Budget: Experience at U.C.L.A.
}

Mr. Vosper is assistant librarian, University of California at Los Angeles.

$T^{N}$ THE winter of 1945 a new administra1 tion of the University of California Library, Los Angeles, found it desirable to review the basis for allocating the annual book budget. The reasoning behind the inherited system, one that had apparently been in force since the earliest days of the library, was not apparent. There was no obvious relationship among the sums allotted to various departments or fields, and because of a practice of carrying forward from year to year a record of previous departmental overdrafts and credits, individual allocations were awkwardly carried out to the second decimal.

Obviously wise planning in the use of his book budget is the librarian's foremost responsibility. Other important matters bespeak his attention, but only by careful attention to the book budget can he build an effective book collection.

For these reasons it was imperative that we do some thinking at U.C.L.A. As a preliminary step comparative information and experience was sought, but because the surprisingly modest literature of this much discussed subject did not answer the questions in mind, a letter was sent to 14 university libraries asking for general advice and for particular details of local practice. ${ }^{1}$

The questionnaire assumed the division of the budget among subject fields or teach-

${ }^{1}$ Columbia, Illinois, Indiana, Iowa, Iowa State, Johns Hopkins, Joint University Libraries, Michigan, Minnesota, Nebraska, North Carolina, Northwestern, Prince. ton, and Stanford. ing departments, and as a matter of fact this is the case in most libraries, except insofar as endowed funds have specific limitations. The wealthier private institutions employing principally endowed funds have another kind of budgetary procedure altogether. It is still possible, however, to consider operating a general appropriated book budget on a non-allocated basis, and at least one institution is experimenting in that direction. If the budget were sufficiently generous to permit the librarian to buy everything he and his colleagues wanted, such a common pool would be easy to administer. We are faced with the fact at U.C.L.A., however, that even a generous book budget is always inadequate, and we feel that some system of allocation is desirable at this stage as a planning device to help guide the growth of the book collections.

The replies to the questionnaire are not subject to statistical analysis, nor do they immediately reveal any common or best pattern. From the cumulative experience, however, some generally useful information was received, and several basic principles or practices for division of the budget can perhaps be derived : (I) Centralized control over all book funds is essential to good planning. (2) Flexibility is a primary requisite of any system. There should be some reasonable balance among like parts. (4) A relatively large reserve fund should be maintained for emergency buying. (5) There should be a relatively sizeable fund at the librarian's disposal for general and interdepartmental buying. (6) There is considerable value in 
a single budget for all subscriptions. Separate financing for current buying and for retrospective buying may be desirable. (8) Division of funds among fields should be made with as much objectivity as possible, but common sense is probably more useful in this task than any presently known statistical formula. (9) Bases for division of the budget and results of the division should be public information, not only for the local faculty and staff but also for other librarians.

(I). It is virtually a truism that the librarian or the librarian and his advisory committee should have central control over or knowledge of all funds for book buying. Only in this way is good administrative planning possible. In the few cases where budget grants are made directly to departments it is agreed that this poses awkward problems.

The U.C.L.A. Library Committee has officially stated that it must take into account all book funds in its planning. This committee is appointed by the Academic Senate to "participate with the librarian in matters relating to the library budget, the formulation of library policies, the allocation of space, and the apportionment of funds" and to "serve as liaison between the faculty and the library administration in all matters of library policy...." A system of branch libraries reporting to the librarian has been established in very recent years, and for this reason the committee has been concerned also with book funds budgeted directly to professional schools and colleges.

(2). The need for flexibility is commonly recognized, but librarians of at least two major universities complain that they must still grapple with rigid allotments to teaching departments. A system of allocations that is frankly experimental, with regular arrangements for review and for emergency alteration during the year, as well as for necessary change from year to year, permits more ready help to new fields and more effective advantage from unusual opportunities in the book market.

The book market, particularly the antiquarian, is hardly predictable, and the wise librarian is the one whose funds are fluid and can be shifted to meet the market. Unfortunately departmental interests are often strongly entrenched and a librarian has trouble removing long standing privilege or advantage. As one librarian replied, "A department accustomed to receiving \$1500 annually feels distress if this amount is cut to $\$ 500$, even though it can be shown that few books have been bought during the past year by the unit concerned, and indeed that in the present state of the book market ... it would be impossible to spend more than $\$ 500$ advantageously." The most vicious result of course may be that some funds remain unencumbered, to revert at the end of a fiscal period, even though other funds prove inadequate.

The same librarian was disturbed by another common and bad practice whereby some departments may break the allocation down again within the department and thus permit "an undesirable hoarding on the part of individuals which matches the hoarding of the departments themselves." Such a multiplied inflexibility can result in the inability of a solvent department to buy books in a new aspect of its field. Department politics come into play, and junior men in new areas of research or teaching have extreme difficulty getting funds even though their needs may be greater because new.

Present practice at U.C.L.A. is to notify departments or committees in July that allocations are tentative, subject to review on February I when overly fat allotments can be trimmed and needy ones fattened with special grants. Departments are also informed that the pattern of initial allotments in the present year will not of necessity be 
followed in the next year. Fresh allocations are now made each year.

(3). As was suggested earlier, the primary value of any system of allocations is that it helps the librarian plan the growth of his book collections from year to year. Some librarians who make no formal allotments, do keep record of expenditures by subject divisions in order at least to keep track of developments. There is a common pragmatic approach which says that funds should be turned over readily to active departments and the weak ones let lag behind. This is the "squeaking wheel" principle which is of course easy to accede to, but carried too far this principle removes from the librarian any moral obligation for assuring a well-rounded collection or for planning beyond the present. One librarian representing an extremist, but fortunately minority, point of view replied that "Unfortunately, some of our library schools have befuddled the thinking of college librarians and there are many ... who think it is their responsibility to select books. This is presumptuous." More frequently however it is apparently assumed that the librarian should take a strong part in assuring balanced growth. The failure of a weak department to buy, even for a few years, can cripple the work of other departments and result in permanent gaps in the collections. As another and more vigorous respondent said, "Obviously, research in almost any science will depend upon strong collections in related fields." Some respect for balance among allotments in related fields will help keep this problem under control.

The new system at U.C.L.A. sets up a sequence of six quite arbitrary levels of allotments (i.e. \$100, \$300, \$650, \$1000, $\$ 1500, \$ 2000)$. Some attention is then given to keeping related fields with comparable book needs in the same category even when other factors, such as size of faculty, etc., might suggest otherwise.

(4). There was virtually complete agreement among all queried that a sizeable amount of the budget should be retained as a reserve fund to use for emergency opportunities or for expensive or en bloc purchases. Several librarians strongly urged this case. Said one, "If the library wants to be in a position to provide a maximum amount of assistance . . . it is essential that a substantial portion of the book appropriation be reserved and not allocated to teaching departments." Replied another, "I should strongly recommend that whatever you do, you maintain a sizeable fund for bloc purchases, making long-range planning possible."

This aspect of budgeting has been of particular importance at U.C.L.A. because as a young library (founded 1919) it still has particular need for back files of journals and can advantageously make bulk purchases without undue concern about duplication. Consequently, the Library Committee has traditionally held a large sum in reserve each year. The only recent alteration has been to make the reserve fund more fluid. In the past each purchase against the reserve fund had to be voted on by the whole committee. Faculty committees are notoriously difficult to assemble, and polling by telephone is suspect because of inadequate discussion. Consequently many rare opportunities to buy journal sets in the open market were lost through delayed action. Recently, therefore, a second series of allocations has been made in addition to those for regular book purchases. These funds, locally called "free sets funds," are given in original amounts of $\$ 300$ each to nearly every department. The department may then on its own initiative, subject only to the librarian's agreement, spend this money for back journal files or other expensive purchases. Its funds expended, the department may call on the 
committee's reserve. This allocation also is subject to review on February 1. As a result of this flexibility we have had far greater luck in the antiquarian market. Moreover, there is somewhat more assurance that all fields will share equally; at least the opportunity is clear.

(5). With equal unanimity it was agreed that the librarian should have disposition of a fairly generous sum to buy books of general interest or books that fall between fields. At least two librarians particularly advised that this aspect of the budget should be-strengthened and small allocations made to departments.

Present practice at U.C.L.A. is to direct Io per cent of the whole budget toward this end and to amplify this amount with any extra funds available at the February reviewing period.

(6). The response to the questionnaire generally supported also the Wilson and Tauber report that "The funds for periodicals [and] continuations ... , unlike those for books, are usually treated together as part of the general library budget instead of being allocated among the various university departments." ${ }_{2}$ This approach is important because of the many omnibus learned journals and because the library policy toward continuing subscriptions needs to be consistent.

The evidence thus gained was sufficiently strong to effect a change at U.C.L.A. to the use of a general budget for subscriptions.

(7). Librarians of several of the larger libraries pointed out that allotments to departments are intended to cover only books currently published in the various fields, not older materials. Retrospective buying is then financed by special grants. The advantages of this approach are that special

${ }^{2}$ Wilson, Louis R. and Tauber, Maurice F. The University Library. Chicago, University of Chicago Press, 1945, p. 84 . attention is given to the vital task of keeping currently abreast of publication and that the filling in of gaps can be effected on a planned and systematic basis.

The matter is under serious consideration at U.C.L.A. where there is always violent strain to make the budget cover both current books and the seemingly endless need for older materials that is a heightened problem in a young institution.

Although there is not a strict separation of current from retrospective buying, there is regular provision for grants to finance special projects. In some cases these provide for general or interdepartmental needs, as for folklore and the history of science. In others they are intended to strengthen weak or neglected aspects of a general subject area. Thus attention can be given to the needs of an instructor brought in to teach new courses, or a department intending to commence doctoral work can bring its book collections up to standards agreed on by the graduate dean and the librarian.

(8). Some of the most interesting of recent writing on this whole subject is in the Coney and Ellsworth discussions of the possible use of mathematical formulae. ${ }^{3}$ Both writers marshal information on the various factors capable of statistical analysis, such as size and maturity of the faculty, research activity, number of students in various grades, etc. Much useful information can be secured by this method, and the use of even partial formulae can help to break up a solidified status quo. The present conclusion of these discussions, however, is that the major factors are still unknowns and that the weighting of factors brings a large amount of subjectivity into even this type of approach. Among the (Continued on page 259)

\footnotetext{
3 Coney, Donald. "An Experimental Index for Apportioning Departmental Book Funds for a University Library." Library Quarterly $12: 422-28$, July 1942 ; and Ellsworth, Ralph E. "Some Aspects of the Problem of Allocating Book Funds Among Departments in Universities," ibid., p. 486-494.
} 
undertake to supply cards printed prior to the date of the completion of the agreement with any given library. In cases in which an agreement is reached with a library which has purchased complete sets of printed cards in the period since the effective date of the cancellation of depository sets of cards, the Library of Congress is prepared to credit the recipient library with the cost of such cards. This last undertaking will lapse as of December 3I, 1949.

(g) All agreements made under this announcement are subject to reexamination at 5-year intervals. In any case of cancella- tion by the Library of Congress, the recipient library will be given one year's notice.

3. The Library of Congress will welcome requests for cards for the purposes mentioned herein from the libraries which may be eligible and which are willing to accept the conditions named above. A period of six months from the date of this announcement will be allowed for the filing of applications before action is taken on any of them, in order that the Library of Congress may make the choices, where there are alternatives, best calculated to advance the national bibliographical interest.

\section{Allocation of Book Budget}

(Continued from page 218 )

significant unknown factors that cannot, at least now, be resolved statistically are the present strength of any particular book collection, the cost of adequate or complete coverage of a field, etc. Gradually, notably through the Farmington experience, we will learn more about costs. If others will follow the lead of Coney and Ellsworth in searching the subject, we may solve other problems. But as one of these writers replied to the questionnaire, "It is not possible at the present time to arrive at an objective formula," but if the formula study is used "with discretion and common sense" it may have some usefulness.

Discretion and common sense, then, with an honest attempt at the kind of objectivity that prevents the budget from becoming a political plum, are probably more useful in balancing all obvious factors than any "scientific" procedure. In practice this approach is apparently the one used at many libraries, including U.C.L.A., at the present time. Wilson and Tauber seem to agree. ${ }^{4}$

(9). Although one librarian reported that he purposely did not do so, it is com-

\footnotetext{
Op. cit., p. 84-88.
}

mon practice to make known to the faculty the size and use of allocations. Such practice seems only good public relations, although it can be argued that knowledge of an unusually solvent fund may encourage wasteful buying.

The library administration at U.C.L.A. has taken the open book as a first principle in its relations with the faculty, and the Library Committee has purposely published its decisions on budget matters in annual and special reports to the faculty.

As is common with questionnaires, most respondents to this one asked to be informed of results. The writer too, after his experience, feels most strongly that there is a great need for more study of this whole subject and for more information on current practice. If, for example, several librarians would regularly record the details of book fund allocations and expenditures in a series of annual reports, we would have on hand a body of information of potentially great value in any pragmatic or theoretical approach to the problem. But of course this shortage of knowledge is common in many library fields. 